\title{
Padre Daniel Pedro Marques de Oliveira: racialização e conflito na Província do Amazonas - 1850 -1889
}

Tenner Inauhiny de Abreu ${ }^{1}$

Resumo: $O$ presente artigo pretende abordar questões referentes ao processo de racialização em torno do personagem do padre "pardo" Daniel Pedro Marques de Oliveira, que durante a década de 1870 foi deputado Provincial no Amazonas. Fato este que não o livrou do preconceito arraigado contra os ex-escravos e libertos, em uma sociedade marcada por hierarquias sociais.

Palavras- chaves: raça, racialização e escravidão.

Abstract: This article intends to address issues relating to the process of racialization around the character of the priest Daniel Pedro Marques de Oliveira, that during the decade of 1870 was Provincial Deputy in the Amazon, not the rid of deep-rooted prejudice against the former slaves and free blacks in a society marked by social hierarchies.

Keywords: race, slavery and racialization

\section{Introdução}

Durante muito tempo a história contada nos bancos escolares e nos livros (didáticos ou não) silenciou de maneira sepulcral a respeito da presença ou mesmo da contribuição da África e seus descentes no Amazonas à época do Império. Paira sobre a trajetória de homens e mulheres negros da região uma poderosa (e arraigada) força discriminatória que oculta a importância das culturas africanas para a formação política e social da sociedade amazonense. Estas curtas páginas se propõem a lembrar o que a muitos interessa esquecer: a inegável presença e influência de africanos e seus descendentes na formação da sociedade amazonense.

Comecemos pelo ilustre e desconhecido deputado provincial, Daniel Pedro Marques de Oliveira. Homem negro, cuja trajetória se pautou pela proteção a fugitivos do cativeiro, pela denúncia de escravocratas violentos, pelo incentivo à emancipação, e por inúmeras depreciações de cunho racial sofridas durante sua vida pública. Como é notório, vale ressaltar que a presença africana na Amazônia está ligada ao drama da escravidão e do infame comércio de almas que se inicia no século XVII e atinge o século XIX. Entretanto, a população negra do Amazonas não era formada apenas por escravizados. Na segunda metade do século XIX, por exemplo, mais de $80 \%$ de

1 Professor da Universidade Estadual do Amazonas. 
homens e mulheres negros da província eram livres (entre nascidos livres e alforriados). Dentre estes, estava o vigário Daniel, padre e professor de primeiras letras na Vila de Silves.

\section{$O$ caso do padre pardo}

Em janeiro de 1874, o padre Daniel Pedro Marques de Oliveira denunciou ao Presidente da Província, que a mulata Benedita, liberta desde agosto de 1873, estava sendo mantida irregularmente como cativa na Vila de Silves, por um homem chamado João Roiz Terço. Benedita é descrita pelo padre como "mulata" e "infeliz brasileira". Portanto, aos olhos do sacerdote, ele estava defendendo os direitos de uma cidadã. Daí que ele descreva a situação irregular perante a lei como zombaria, e afirma que a mulata sofria tratamento bárbaro pelo seu algoz, caracterizado como homem violento e de péssimos precedentes. $\mathrm{O}$ texto faz alusão à carta de alforria da mulata, conforme veremos a seguir.

(...) Pela inclusa carta de alforria, verá V.Exa. que a mulata Benedita é liberta desde 30 de Agosto de 1873. Sendo, porém, público e notório nesta vila, que essa infeliz continua a viver até esta data debaixo de um cruel cativeiro, sofrendo que diariamente (?) os mais bárbaros tratamentos de João Roiz Terço $^{2}$, homem de gênio violento e de péssimos precedentes; que, por vezes, tem aqui zombado da lei e da autoridade, recorro à V. Exa., rogando-lhe se sirva garantir a liberdade dessa infeliz brasileira. Levando este fato ao conhecimento de V. Exa., creio que cumpro um dever inerente ao meu ministério, qual o de proteger os infelizes e desvalidos, máxime os que estão confiados à minha jurisdição espiritual. (...). (ARQUIVO PÚBLICO DO ESTADO DO AMAZONAS - Livro de Ofícios remetidos pela Câmara Municipal de Vila Bela, 1873)

Como podemos observar no texto acima, para padre Daniel, ao denunciar as sevícias cometidas contra a liberta Benedita, estava apenas "cumprindo um dever inerente ao seu ministério", de "proteger os desvalidos e os infelizes." Este era o papel do clérigo? Ou sua "jurisdição espiritual” se confundia com sua atuação política?

Esta não era a primeira nem a última vez que o dito padre Daniel estaria envolvido em questões polêmicas. Pardo, livre, acusado de diversos crimes, teve forte presença no cenário político da Vila de Silves, sendo virulentamente perseguido pelos seus adversários

2 As partes em negrito nesta e nas próximas citações são grifo nosso. 
Sankofa. Revista de História da África e de Estudos da Diáspora Africana Ano VI, NXII,

Dezembro/2013

políticos, por conta de sua condição (liberto) e sua cor (pardo).

Em 1863, existiu uma eleição anulada por sua participação na mesa eleitoral. Em 1870, ele terminou a eleição provincial empatado em número de votos com Thomaz Luiz Simpson (31 no total) e quase assume o posto de deputado após a anulação da eleição de José Bernardo Michilles. Só não assumiu porque o substituto de Michilles foi escolhido por sorteio. (ANAIS DA ASSEMBLEIA LEGISLATIVA DO AMAZONAS DE 1870-1871. Manáos: Impresso na Typographia Industrial, p. 02-04, 1882)

Finalmente, em março de 1872, após mais de uma década de acirradas lutas, o sacerdote chega ao então posto de deputado da assembleia provincial. (ANAIS DA ASSEMBLEIA LEGISLATIVA DO AMAZONAS DE 1870-1871. Manáos: Impresso na Typographia Industrial, p. 02-04, 1882)

Estamos, portanto, diante de uma personagem que durante quase uma década esteve no centro das disputas políticas do período provincial no Amazonas, carregando consigo o peso da condição de liberto e as marcas de sua origem.

Foi uma trajetória política difícil. Em fevereiro de 1859, por exemplo, o Jornal Estrella do Amazonas noticia a prisão do sacerdote por agressão a uma autoridade:

No dia 15 - De ordem do sr. Dr. Chefe de policia o vigário da Villa de Silves, Daniel Pedro Marques de Oliveira e o alferes da guarda nacional Fidelles Alves da Costa, pronunciados pelo espancamento do ex subdelegado da mesma Villa Olimpio da Costa dos Santos por perjúrio (ESTRELLA DO AMAZONAS 9 de fevereiro de 1859)

Este foi o fato de origem que foi utilizado inclusive para o impedimento da participação de padre Daniel nas eleições provinciais, em 1863. Foi então solicitado o voto em separado do sacerdote, por conta do processo em que estava envolvido motivado pela suposta agressão ao sub-delegado de Silves. Por isto, a mesa eleitoral então recebera um requerimento solicitando o voto em separado do padre, sob alegação de que ele estava sendo processado, o que suspenderia seus direitos políticos. Meses depois o padre seria absolvido das acusações: 
A QUINZENA. - Manáos 9 de Janeiro (...) Domingo procedeo-se a eleição dos 8 membros e 4 suplentes d'Assemblea Legislativa Provincial, que devo dar o circulo d'esta Capital, sahindo eleitos os Deputados os Snres. Custodio Pires Garcia, Manoel Rodrigues Checks Nina, Vicente Alves da Silva, Dr. Jose Antonio de Freitas Junior, Padre Daniel Pedro Marques d'Oliveira, Joaquim Firmino Xavier, José de Carvalho Serzedello, e Francisco Antonio Monteiro Tapajos, que obtiverão maioria de votos na respectiva eleição; e Supplentes os Snres. Padre Manoel Lucupertino Salgado, Francisco de Paula Bello, e Manoel da Silva Ramos. A eleição ocorreo calma e sem a menor intervenção da autoridade, dandose apenas uma pequena irregularidade de Um dos Eleitores requereo em termos que o voto do Eleitor Padre Daniel fosse tomado em separado, visto como está elle sujeito aos efeitos de uma pronuncia em cauza crime, e por tanto suspenso dos direitos políticos. Este requerimento porem, que tinha por fim arredar da eleição toda e qualquer ilegalidade e no qual devia votar todo o Collegio Eleitoral, foi peremptoriamente decidido pela Meza, que o dito Eleitor votasse englobadamente com os outros. (ESTRELLA DO AMAZONAS, 11 de janeiro de 1860)

Pozza Neto (2011, p. 80) $)^{3}$ estudou do crescimento do movimento emancipacionista na Província do Amazonas, entre as décadas de 1850 e 1870. Neste contexto, padre Daniel parece ter tido um papel de destaque no cenário político contra os interesses escravocratas. Foi inclusive acusado de acoitar escravos em fuga.

Em 21 de março de 1860 o jornal Estrella do Amazonas noticia fato curioso a respeito do acoitamento de 8 escravos na Vila de Silves. De acordo com a notícia, autoridades da Vila estavam envolvidas no caso:

Denunciados como escravos 8 individuos, que na villa de Silves acoutados escarnecião da lei e zombavão de direito de propriedade servião até cargos públicos; um de porteiro da Camara Municipal e outro de cabo de trabalhadores. (ESTRELLA DO AMAZONAS 21 de março de 1860.)

Interessante é que os escravos acoitados serviam como funcionários públicos na localidade, evidentemente com a "vista grossa" de autoridades locais:

O subdelegado e o commandante de trabalhadores, e o presidente da câmara são indigitados como protectores desses escravos, em consequência do que forão imediatamente demitidos os primeiros, a bem do serviço publico, e consta que o dr Chefe de Policia do Pará para averiguar o facto do acoutamento.

3 Dos dados coletados a respeito das alforrias na Província do Amazonas o autor afirma que o número de concessão de alforrias se concentra particularmente na década de 1870. 
(JORNAL ESTRELLA DO AMAZONAS 21 de março de 1860).

De acordo com o noticiado no jornal, foram capturados na Vila de Silves sete dos oito escravos fugidos, dentre eles uma escrava parda de nome Ignez com seus cinco filhos. Em conformidade com a nota, estes eram escravos de um proprietário paraense de nome Amanajás. O acoitamento gerou a destituição das autoridades envolvidas no fato.

Voltemos à história do padre Daniel. Ele nasceu em 28 de março de 1828, na cidade do Pará (Belém), filho de Anna Joaquina, mulata, que era escrava de seu pai José da Costa Albernaz. Daniel teria sido liberto na pia batismal, de acordo com suas alegações.

Mas tal trajetória é polêmica. Uma fonte de informações importante é o texto seguinte do jornal $O$ Catechista, que busca desconstruir a argumentação do padre:

O novo testamento, diz-nos o Rvm, proclama todos os homens livres, "logo sou livre"!. He verdade quanto ao que diz o Evangelho; mas esta verdade, e a consequência que tira estão em flagrante contradição com os factos no brasil nem todos são livres e prova está para si, mais que patente pois que nos confessa no seu granzel que sua mãe era escrava de José da Costa Albernaz, nos seguintes arrancos d'uma confissão pungente: meo presadissimo pae único que, na terra $P O D E$ chamar-se senhor de minha idolatrada mãe ...

Logo a citação nada vem ao caso e me nos a consequência; pois que apesar do Novo Testamento, proclamar todos os homens livres, a mãe do Rvm, Sr. Daniel era escrava. (O CATECHISTA, 12 de janeiro de 1863.)

Seja como for, talvez esta origem tenha sido o fato que tenha despertado tanto o ódio por parte de seus adversários, que tentaram desqualificar seus discursos e ações políticas. As querelas presentes nas páginas dos jornais ultrapassam as disputas entre interesses políticos diferenciados, ganhando conotação de ódio racial e preconceito contra a condição e a cor do padre Daniel.

Ao buscar atacá-lo politicamente, as autoridades veiculavam pelos jornais, acusações e impropérios que deixam transparecer de que maneira a elite governante da época via os libertos, os não brancos. Sem dúvida, é uma mostra de como as experiências do cativeiro marcavam profundamente uma sociedade rigidamente estratificada e hierarquizada, em que a cor se configurava como um dos aspectos discriminatórios mais 
Sankofa. Revista de História da África e de Estudos da Diáspora Africana Ano VI, NºXII,

Dezembro/2013

poderosos.

O certo é que, a partir de 1863, o padre Daniel Marques de Oliveira esteve no centro das disputas políticas da província do Amazonas. Como dito, as eleições foram anuladas por conta de sua presença na mesa eleitoral. Era um fato proibido pelas leis imperiais, que restringiam os direitos dos libertos ao exercício do voto, pois os mesmos não podiam ser candidatos. Um ex-escravo como ele, portanto, não poderia exercer o comando da mesa eleitoral, muito menos ser candidato.

O jornal $O$ Catechista publicou o assento de batismo do padre visando comprovar a sua condição de ex-escravo. O objetivo era restringir os direitos de participação política deste, por conta de sua origem:

(...) [Certidão] - Certifico que revendo o Livro decimo septimo de assentos de baptismo da freguesia da Sé nelle a folhas uma até verso se acha o assento seguinte - Aos dez dias de Maio de 1830 annos, nesta cidade do Pará em a câmara Eclesiastica me foi apresentada uma peticao de José da Costa Albernaz, em seu seguimento uma certidão do Theor seguinte. - No dia vinte e oito de março de mil oitocentos e vinte oito nesta capella de Nossa Senhora da Estrella da fazenda de Pernambuco, baptisei solememente e puz os Santos Oleos ao inocente Daniel filho natural de Anna Joaquina, mulata ESCRAVA de José da Costa Albernaz, (...). (O CATECHISTA, 5 de dezembro de 1863)

$\mathrm{O}$ articulista do jornal Catechista defende seu ponto de vista a respeito das alegações de que o padre era liberto ou mesmo escravo afirmando que: "Difficil é a situação do jornalista imparcial, quando forçado pelo dever discute um acto publico, e vêse depois de frente para sustentar suas opiniões com uma questão pessoal, e odiosa. Tal é nossa actual situação." (O CATECHISTA, 12 de dezembro de 1863)

A visão de imparcialidade tinha duplo objetivo. Em primeiro lugar, convencer o leitor da veracidade dos fatos narrados. Secundariamente, esconder a vinculação de interesses expostos nas colunas dos jornais da época.

Sidney Chalhoub em Trabalho, Lar e Botequim faz inclusive alusão à forma como as notícias eram produzidas no período. Referindo-se a Lima Barreto, afirma que, em alguns casos, era absolutamente corriqueiro entre os articulistas o uso da criatividade e a invenção dos fatos (maior floreio) principalmente nas chamadas das notícias.

No caso do Jornal Catechista, o articulista reitera sua posição, alegando que o padre Daniel, embora oficialmente liberto, "se sinta escravo": 
Sua Rvma. Porem, pela Estrella no. 795 de 2 do corrente, accusanos de libellista, o porque isto dicemos e tentando distruir nossa asseveração de seo estado liberto, cego apaixonado e mostrado sua ignorância, confessa se sintia escravo! (O CATECHISTA, 12 de dezembro de 1863).

A ideia da imparcialidade do jornalista e, portanto, da suposta neutralidade da matéria publicada em si, em verdade defendia o ponto de vista do próprio jornal. Ou seja, a tentativa de convencer o leitor de que as eleições da Província do Amazonas daquele ano de 1863 deveriam ser anuladas devido à condição de liberto padre Daniel (ex-escravo, pardo):

Em o no. 83, discutindo as nulidades insanáveis das eleições porque passamos à pouco, fomos levados a mostrar entre outras causas, o ter sido o collegio da capital presidido por um liberto. Esse liberto, que apontamos então é o sr. Padre Daniel Pedro Marques de Oliveira. (O CATECHISTA, 12 de dezembro de 1863)

Este por sua vez, ao tentar se defender das acusações que sofria (a tentativa de impedimento da sua participação nas eleições provinciais), usou também os jornais para responder as acusações sofridas. Citando trechos das ordenações Filipinas e citações do Novo Testamento alega ser cidadão livre:

A ordenação [Liv. 4 Tit. 92 pr. e Reper] nosso direito pátrio civil proclama que o filho que o homem solteiro peão houver de alguma escrava sua he livre e lhe sucede na herança: eu succedi na herança de José da Costa Albernaz, senhor de minha mãe logo sou livre. (O CATECHISTA, 12 de dezembro de 1863)

Mas as acusações continuavam no jornal $O$ Catechista:

O Rvm. escravo se não provar com documento que foi alforriado, ou não nos mostrar que o tribunal para o qual tentou ação de prescrição o considerou liberto. O Rvm. jamais pode ser livre na expressão da lei, na sua letra clara. Porquanto ficou provado (...) ter nascido de ventre escravo: e a lei diz claramente que só pode gozar de liberdade, se alcançar alforria. (...) O Rvm. o mais que pode subir na escala social é a camada dos LIBERTOS (O CATECHISTA, 12 de dezembro de 1863) 
A impossibilidade de subir na escala social, imposta ao padre Daniel, está presente no texto acima. Ele expõe a visão que se tinha a respeito dos grupos ligados aos escravos e ex-escravos. Neste caso, a condição intermediária destes, por sua origem. O escravo jamais seria um cidadão. Seria no máximo um liberto. E por isso mesmo com restrições à sua cidadania.

Há na história do padre Daniel uma série de aspectos importantes que revelam como a questão racial é manejada nos debates jornalísticos, que utilizavam sua "condição" social e cor (por vezes descrito como pardo e liberto, por vezes como preto e escravo) para deslegitimar seus discursos e ações. Para seus “inimigos políticos”, ele seria para sempre um ex-escravo.

Pode-se observar outro exemplo disto no jornal Estrella do Amazonas em Agosto de 1860, quando este publicou uma nota assinada pelo então escrivão Manoel do Nascimento Figueira, acusando o referido padre de querer ampliar sua atuação para além dos assuntos eclesiásticos. A nota do jornal é bem enfática ao retratar tanto a visão negativa a respeito da origem étnica deste (atacando a sua índole e faz alusão à cor da sua pele). Chega a ameaçá-lo diretamente a cadeia e ao açoite:

O padre mestre não se contenta com o campo de sua parochia para fumentar a desordem, quer campo maior e achou que eu devia servir-lhe de pasto a sua loquacidade. Enganou-se completamente por que estou disposto a não despor mais de minha dignidade para dar troço a semilhante besta, a menos que não tire a mascara e appareça a peito descoberto, por que quero metel-o ainda uma vez na cadêa; ouvio padre mestre? Si esta lição, padre mestre, não vos serve ainda, então convencerás ao publico sensato, que só vergalho é que vos pode indireitar; mas qual! Preto quando não suja, tisna. (ESTRELLA DO AMAZONAS, 25 de agosto de 1860).

A ameaça é evidente: "só vergalho pode endireitar o padre". Logo depois o preconceito toma conta das páginas do jornal: "preto quando não suja, tisna"! A presença de tais ofensas e ameaças mostra que a luta virulenta contra as ações políticas do sacerdote ultrapassam os posicionamentos políticos. Recaiam no campo do preconceito de raça, particularmente àquele presente no século XIX, em que a inferioridade dos negros era 
reforçada por sua suposta impossibilidade de alcançar à civilização pelas experiências do cativeiro.

No mesmo mês e ano, o jornal Estrella do Amazonas volta a ameaçar o padre Daniel com acusações sérias. Afirma, categoricamente, que ele era o "evangelista do deboche e da prostituição". Ademais, aludindo ao fato dele lecionar para jovens, acusam-no de aliciar suas alunas, mulheres casadas e jovens inocentes (se aproveitando de sua condição de padre e professor) e de ter falsificado a carta de alforria de sua mãe para poder conseguir sua ordenação:

O padre mestre de Silves é o evangelista do deboche e da prostituição, solicita intra e extra confissões as mulheres casadas, solteiras e donzelas, e como prova cita-se d. Inácia, as menores que por suas artimanhas estiveram depositadas em sua casa aos seus desejos, e as meninas que (coitadinhas!) iam a sua casa a título de aprenderem a ler, beber o veneno da imoralidade (...) mandou chibatar e por em ferros um cidadão mais livre do que ele; conseguiu por suas astucias do tabelião João Corrêa registrar no seu cartório uma carta de liberdade, da preta f. sua mãe por ocasião de ser preterido em sua ordenação em consequência de ex defectu liberdatis (...). (ESTRELLA DO AMAZONAS, 22 de agosto de 1860).

Apesar da gravidade de tais acusações, elas não impediram o padre Daniel de conseguir a abertura de uma escola em Silves, em novembro do mesmo ano. Algo que se pode observar do próprio jornal Estrella do Amazonas:

De Daniel Pedro Marques de Oliveira [Vigario Collado da Vila de Silves], pedindo permissão para abrir uma escola na freguezia de Silves, de grammatica latina, Franceza, retorica, e Philosophia racional. - Concedo a authorização requerida. Passe-se o competente titulo. (ESTRELLA DO AMAZONAS, 28 de novembro de 1860.).

A série de notas do jornal Estrella do Amazonas fazem ainda menção a supostos furtos que este terá feito de imagens e relíquias da igreja em que ele trabalhava ${ }^{4}$ :

4 O Jornal Estrella do Amazonas de 24 de março de 1860 solicita o envio da copia do processo que absolvia o Padre Daniel de uma destas acusações: "Ao juiz de direito interino da commarca da capital, determinando-lhe que envie com a possivel brevidade copia authentica da sentença proferida contra o vigario da villa de Silves Daniel Pedro Marques de Oliveira, no processo que foi submettido ao jury na $2^{a}$ sessão do anno passado, bem como a da absolvição em consequencia da decisão do jury". O mesmo jornal em agosto ignora absolvição do sacerdote em uma das acusações. 
(...) furtou 200\$ rs. dos cofres dos pontificaes, quando encarregado dessa repartição na sé do Pará; furtou segundo a participação do juiz de paz as joias das Imagens das igrejas de Silves e Jatapú finalmente, tem sido submettido a 3 ou 4 processos e prezo pelas suas altas virtudes. Tudo isto é meramente hypothetico, mas que o respeitável publico, caprixoso como é, pode converter, querendo, em verdades mathematicas. (ESTRELLA DO AMAZONAS, 22 de agosto de 1860).

Notemos a partir da citação acima que o próprio texto do jornal afirma que todas estas acusações são meramente hipotéticas. Mas não se deixa de destacá-las, dizendo que o próprio público, caprichoso como é, pode convertê-las em "verdade matemática".

No mesmo contexto, na crônica A Quinzena, o padre é retratado como "pescador de águas turvas", que teria por interesse transtornar a sociedade:

\begin{abstract}
A Quinzena
Manáos 24 de agosto de 1860

Todo corre placidamente; apenas um ou outro pescador d'aguas turvas trabalha com afan por transtornar este estado lisongeiro Mas temos fé nos brios dos amasonenses que serão em tempo repellidos, como merecem, e conhecerão que o cabucolo do Amazonas tem nas suas flexas e fructos silvestres todos os elementos para resistirem a imposições de intruzos, que não teem o menor direito de intervir na direção de sua sorte. (...). (ESTRELLA DO AMAZONAS, 24 de agosto de 1860.)
\end{abstract}

O objetivo é mais uma vez questionar a intervenção do padre em assuntos diversos na comunidade de Silves. "O pescador de águas turvas" seria uma alusão a seu caráter? A sua cor da pele? Ou ambos? Importante frisar que o texto encerra-se afirmando que de este não teria direito de interferir na sorte do "caboclo do Amazonas". Notemos aí a presença da visão do caboclo e a sua condição e herança da cultura indígena vista como oposta a civilização. Neste sentido, a referência estereotipada à cultura material (portar flechas e comer frutos silvestres) mostra também o preconceito contra os indígenas da época.

As imposições de um "intruso" referem-se ao fato do padre Daniel ser de fora da Província, nascido como vimos em Belém, no final da década de 1820. Assim, o artigo acima demonstra a preocupação acerca da atuação política dele, pois este se utilizaria, 
segundo esta visão, de sua posição para intervir na vida da sociedade amazonense. O sacerdote é caracterizado negativamente, e a forma como é definido sempre alude ao fato de ser liberto, escravo e/ou preto, de acordo com o teor dos textos.

Novamente, no jornal Estrella do Amazonas de 20 de junho de 1860 aparece tanto a preocupação quanto ao peso político do padre Daniel - comparado a um "dedo de gigante" -, quanto a sua origem racial: cara branca e língua preta. O texto retoma a ideia de que ele buscava ardis para mascarar sua condição de liberto, utilizando-se de sua posição de padre para gozar dos privilégios de cidadão livre:

Fazemos este pedido não por que não conheçamos pelo dedo o gigante, que (...) tem até hoje, por uma tolerância imperdoável, gozado dos foros de cidadão livre; mas por que queremos ter o prazer de ver a cara branca do - Silviense - e língua preta. (ESTRELLA DO AMAZONAS, 20 de junho de 1860.)

No mesmo jornal, também se retoma a afirmação de que o padre esconderia sua origem e atuaria de maneira criminosa. O que fica evidente quando se alude, mais uma vez, a sua condição "dúbia": escravo ou liberto?

\footnotetext{
Rogo-lhe que tire a máscara, saia dos bastidores e acuse-me a peito descoberto sob pena de ser tido por criminoso escravo ou liberto, que teme a ação da justiça, a que chama perseguição - escravidão - e prepotência o que não podendo defender os seus parceiros escravos, que naquela vila gozavam dos foros de cidadãos. (ESTRELLA DO AMAZONAS, 20 de junho de 1860.)
}

Ademais, vê-se a acusação de que este era um acoitador de escravos. No texto, os escravos são seus "parceiros". Afinal, ambos buscariam gozar da posição de cidadãos, escondendo sua origem e condição.

Por outro lado, em diversas passagens dos jornais os artigos relembra-se a condição de "preta" e escrava da mãe do padre Daniel, mesmo que nos documentos oficiais ela seja descrita como "mulata". Aqui não importa a cor da pele e sim a vinculação a raça, biologicamente falando. Do mesmo modo, como vimos, a própria condição do referido padre é assinalada de maneira dúbia, ora liberto, ora escravo, pardo, preto. 
Aqui recorremos às colocações de Serge Gruzinski acerca da mestiçagem, quando este afirma que:

as relações entre vencedores e vencidos também assumiram forma de mestiçagens, alterando os limites que as novas autoridades procuravam manter entre as duas populações. Desde os primeiros tempos, a mestiçagem biológica, isto é, a mistura de corpos - quase sempre acompanhada pela mestiçagem de práticas e crenças introduziu um novo elemento perturbador (...) Estupros, concubinagens, mais raramente casamentos, geraram uma população de tipo novo, de estatuto indefinido - os mestiços, a respeito dos quais não se sabia muito bem se deveriam ser integrados ao universo espanhol ou às comunidades indígenas (...) Por todas essas razoes, índios negros e espanhóis tiveram de inventar, dia após dia, modos de convívio ou, especialmente os primeiros, soluções de sobrevivência. (GRUZINSKI, 2001, p. 78)

Para Gruzinski, a mestiçagem ocorrida em tempos coloniais por conta do choque da conquista se inscreveu numa fase de expansão da Europa (fortemente marcada pela hibridação biológica, no caso da Península Ibérica) e num contexto de colonização. Ambos os fatores impedem que a mestiçagem americana seja reduzida a um fenômeno cultural. Mais a frente o autor esclarece: "Em geral, as mestiçagens dos tempos modernos dão-se em águas turvas, em leitos de identidade quebradas." (GRUZINSKI, 2001, p. 64)

Nos primórdios da colonização, de acordo com Gruzinski, os mestiços não tinham lugar - do ponto de vista jurídico - na nova sociedade oriunda do processo de conquista, na medida em que esta se encontrava divida entre uma "república dos índios" e uma república dos espanhóis". Tais mestiços eram frutos da hibridação de negras e espanhóis ou negros e índios.

A visão conjuntural desse processo por Gruzinski nós é útil para analisar a sociedade amazonense do século XIX, pois muitas ideias e conflitos que envolvem os atores ali envolvidos ainda estão em processo de mutação.

O choque da Conquista, conforme assinala o autor, obrigou os grupos distintos que formavam a sociedade da América espanhola a se adaptarem ao que o autor classifica como universos fragmentados e fraturados, vivendo em situações precárias, instáveis e imprevisíveis. Afirma que o intercâmbio entre estes grupos era quase sempre rudimentar e conclui: "Estas características marcaram fortemente as condições em que se desenvolveram as mestiçagens da América espanhola, criando, em todos os sentidos da 
Sankofa. Revista de História da África e de Estudos da Diáspora Africana Ano VI, NXII,

Dezembro/2013

palavra, um ambiente caótico, sensivel à menor perturbação.” (GRUZINSKI, 2001, p. 64)

\section{Considerações finais}

Sobre o padre Daniel há muito mais para dizer. De início, é preciso salientar o fato de que se trata do primeiro negro de origem escrava a ocupar o cargo de deputado provincial e, tempos depois, de vice-presidente da Assembleia do Amazonas, nas legislaturas de 1876-77. Desconhecemos caso semelhante em todo o Império Brasileiro.

Mais do que isso, o que contamos aqui de sua história é suficiente para lembrar algo importante: a densidade histórica de um passado recente vivido pela sociedade amazonense, pautada pela discriminação em bases raciais. Apesar da grande influência em Silves, aliado às principais autoridades daquela localidade, Daniel sofreu forte oposição das elites políticas, sobretudo de Manaus, quando este tentava ampliar sua esfera de atuação política. No cerne das acusações e desqualificações que sofreu estava a cor de sua pele e o fato de ter sido escravo, ainda que libertado na pia batismal.

Neste sentido, dizia o editor do jornal Catechista: "no Brasil o fato é que nem todos são livres". Vale acrescentar: muitos, inclusive, viviam num cativeiro ilegal. Também não ajudou o argumento de que fora libertado no ato do batismo. Ainda restava o preconceito de cor. Como sugeria uma das crônicas jornalísticas citadas, ser negro no Amazonas significava possuir uma mancha inextirpável. Implicava, por outro lado, a definição de uma identidade estrangeira para os de origem africana, os tais "intrusos". Eram discursos que buscavam marginalizar (e silenciar) negros e negras da vida pública e de outros "assuntos amazonenses".

\section{Referências Bibliográficas}

\section{Fontes Impressas:}

1 Jornais: Centro de Documentação e Apoio à Pesquisa - CENDAP/Acervo de Microfilmes - Estrella do Amazonas (1859-1860); O Catechista (1863) 
Sankofa. Revista de História da África e de Estudos da Diáspora Africana Ano VI, NºXII,

Dezembro/2013

\section{Falas e Relatórios:}

Arquivo Público do Estado do Amazonas - Livro de Ofícios remetidos pela Câmara Municipal de Vila Bela 1873

\section{Disponível em:}

http://brazil.crl.edu

http://memoria.bn.br/hdb/periodo.aspx

\section{Anais da Assembleia Legislativa}

Anais da Assembleia Legislativa do Amazonas de 1870-1871. Manáos: Impresso na Typographia Industrial, p. 02-04, 1882.

Anais da Assembleia Legislativa do Amazonas do biênio 1872-1873. Manáos: Impresso na Typographia, do Amazonas, p. 02-04, 1882.

\section{Disponível em:}

http://www.aleam.gov.br/Legislacao_1871_1889/

\section{Bibliografia:}

CHALHOUB, Sidney. Trabalho, lar e botequim: o cotidiano dos trabalhadores no Rio de Janeiro da Belle Époque. São Paulo: Brasiliense, 1986.

GRUZINSKI, Serge. O pensamento mestiço. São Paulo: Companhia das Letras, 2001

HOBSBAWM, Eric J. Mundos do trabalho: Novos estudos sobre história operária. Rio de Janeiro.: Paz e Terra, 2000

IANNI, Octavio. Raças e Classes no Brasil. São Paulo: Brasiliense. 1987

LARA, Silvia Hunold. Conectando historiografias: a escravidão africana e o Antigo Regime na América Portuguesa. In: Maria Fernanda Bicalho e Vera Lúcia Amaral Ferlini. Modos de Governar: ideias e práticas politicas no Império Português. São Paulo: Almeida, 2005.

LIBBY, Douglas Cole. A empiria e as Cores: Representações identitárias nas Minas Gerais dos Séculos XVIII e XIX. In: Escravidão, mestiçagens, populações e identidades culturais. São Paulo: Annablume. Belo Horizonte: PPGH-UFMG; Vitória da Conquista: Edições UESB, 2010. 
LIMA, Henrique Espada. Sob o domínio da precariedade: escravidão e os significados da liberdade do trabalho no século XIX. Topoi, v. 6, n. 11, jul - dez. 2005.

MATTOS, Hebe Maria. Escravidão e cidadania no Brasil Monárquico. 2a . Ed. - Rio de Janeiro: Jorge Zahar ed., 2004

MUNANGA, Kabengele. Mestiçagem e identidade afro-brasileira. In: OLIVEIRA, Iolanda (org). Relações raciais e educação: alguns determinantes. Cadernos PENESB 1. Niterói: UFF, Intertexto, 1999.

NETO, Provino Pozza. Alforrias escravas na Província do Amazonas. In: O fim do silencio: presença negra na Amazônia. Belém: Editora Açaí, 2011.

SCHWARCZ, Lilia M. Retrato em Branco e Negro: jornais, escravos e cidadãos em São Paulo no final do século XIX. São Paulo: Companhia das Letras, 2008. . O espetáculo das raças. São Paulo: Companhia das Letras, 1995. . Espetáculo da miscigenação. Estudos Avançados, n. 8, vol. 20, 1994. 